\title{
Developers' Competition Behaviour of Land Reserve in Assembled Buildings Development: Based on Game Analysis Framework
}

\author{
Gangqiang Luo ${ }^{1 *}$ and Qin Wang ${ }^{1}$ \\ ${ }^{1}$ Department of Civil and Construction Engineering, Guangdong institute of Arts and Sciences, Zhanjiang, Guangdong, 524400, China \\ ${ }^{1}$ Department of Finance and Accounting, Guangdong institute of Arts and Sciences, Zhanjiang, Guangdong, 524400, China
}

\begin{abstract}
Based on the perspective of game theory, this paper studies the land reserve competition behaviour of developers in assembled buildings development. This paper studies in detail the land price decision in the unilateral equilibrium model of land market, the lending strategy of commercial bank executives under the banking supervision system, the bank credit demand of developers hoarding land, and the bilateral equilibrium model of credit-land market under the loan game of bank executives. The results show that the equilibrium price of land is positively correlated with the number of developers, the total amount of bank loans available to developers and the basic price of land. There is a positive "vicious" circular transmission mechanism between land price, marginal private interest of bank executives' lending and bank financial support.
\end{abstract}

\section{Price decision in unilateral equilibrium model of land market in assembled buildings development}

Assuming that the supply of land market is a fixed $Z$ and the number of developers is $N$ in a short period of time, developers have different land expected prices $\left(P^{\prime}\right)$ because of the main factors such as the difference of land income and risk expectations ${ }^{[1]}$. It is assumed that $P^{\prime}$ obeys the uniform distribution of the mean value of land basic price $P^{*}$. Obviously, the proportion of developers whose land expected price $P^{\prime} \geq$ land basic price $P^{*}$ plays a key role in determining land market price ${ }^{[2]}$. If the total amount of bank credit available to developers is $N L$ (assuming that all of it is used to purchase land), then the total demand of the land market is:

$$
D=N[1-F(P)] L
$$

Since the total supply of land market is $P Z$, when the land market reaches equilibrium, the total demand for land equals the total supply of land, the following are as follows:

$$
P Z=N[1-F(P)] L, P=N[1-F(P)] L / Z
$$

Since $P$ is evenly distributed within $\left[P^{*}-h, P^{*}+h\right]$, the following are found:

$1-F(P)=\left(P^{*}+h-P\right) / 2 h$, it can be obtained as follows:

$$
P=\left[N\left(P^{*}+h\right) L\right] /(2 Z h+N L)
$$

Formula (3) shows that the equilibrium price of land $(P$ ) mainly depends on the following four variables: the number of developers $(N)$, the amount of bank loans available to developers $(L)$, the basic price of land $\left(P^{*}\right)$, and the degree of difference in the expected price of land $(h)$. The first-order partial derivatives $\left(N, L, P^{*}, Z\right.$ and $h$ are all positive numbers) of $N, L, P^{*}$ and $h$ are obtained by pairwise formula (4).

$$
\begin{aligned}
& \frac{\partial P}{\partial N}=\frac{2 h Z\left(P^{*}+h\right)}{(2 h Z+N L)^{2}}>0 \\
& \frac{\partial P}{\partial L}=\frac{2 h Z N\left(P^{*}+h\right)}{(2 h Z+N L)^{2}}>0 \\
& \frac{\partial P}{\partial P^{*}}=\frac{N L}{2 h Z+N L}>0 \\
& \frac{\partial P}{\partial h}=\frac{N L\left(N L-2 P^{*} Z\right)}{(2 h Z+N L)^{2}}
\end{aligned}
$$

According to formulas (4), (5), (6), the equilibrium price of land is positively correlated with the number of developers, the total amount of bank loans available to developers and the basic price of land ${ }^{[3]}$. At that time, the symbol of formula (7) was positive, which indicated that when the total amount of bank's land credit support to developers exceeded the expected value of land supply calculated by land base price, the equilibrium price of land would increase with the increase of the difference between the reserved price of developers and the expected price of land base (i.e., optimistic expectation with the increase of 
$h$ ). This shows that when the amount of bank credit support owned by each developer is stable and the number of developers increases, or when the number of developers is stable and the amount of bank credit support owned by each developer increases (that is, the total amount of bank credit entering the land market increases), the equilibrium price of the land market will rise ${ }^{[3]}$.

Therefore, when the banking system has an optimistic supply expectation ( $h$ increases), a sharp increase in the number of developers ( $N$ increases) and excessive credit support behavior ( $N L$ increases), the land market price is likely to be seriously overestimated ( $P$ increases). Based on the actual situation of land market and credit market, this paper makes an in-depth analysis of the relationship between optimistic expectations of bank executives, rising land prices and excessive financial support of developers' land hoarding movement in the transitional period of China ${ }^{[4]}$.

\section{Lending strategy of executives of commercial banks under banking supervision system}

Assuming that the senior managers of commercial banks are the specific executing agents of the credit decisionmaking under the banking supervision system in China, whose actual behavior represents the relevant behavior of commercial banks. We can consider that the utility function of the senior bank managers is determined by the following formula:

$$
U_{B}=q R L+w\left[r_{L} L-r_{D} D-C(L, D)-(1-q) F\right]
$$

Among them, $U_{B}$ represents the expected utility of commercial bank executives, $r_{L}$ and $r_{D}$ represent the loan interest rate and deposit interest rate respectively, $L$ and $D$ represent the loan amount and deposit amount respectively, $r_{D}$ and $D$ are exogenous variables. Commercial banks stipulate that the utility coefficient of profits created by bank executives is $\omega$, and $0<\omega<1$. It represents the operating costs of commercial banks, assuming $\partial C / \partial L>0$ and $\partial^{2} C / \partial L^{2}>0$ (i.e., the marginal operating costs of banks are positively correlated with the scale of lending). $R$ denotes the private benefits (such as rebates) that bank executives derive from unit lending. $q$ is probability of seeking personal gain for bank executives without being discovered by bank regulators. Suppose that when bank supervisors discover that bank executives expand lending for personal gain (probability is $1-q$ ), the penalty for banks is $F>0$ (bank executives' personal gain is not confiscated while banks are liable for the penalty) ${ }^{[5]}$.

Since 1998, China's banking industry as a whole has implemented a comprehensive asset-liability ratio regulation, which stipulates that a certain value ratio of collateral $(k)$ must be used as the lending limit ${ }^{[6]}$.
Assuming that the developer's land mortgage value $\tilde{A}$ (random variable) is incomplete information for bank executives and banking regulatory authorities, the latest market price $P$ of land can be obtained by market comparison method [7]. Suppose $\tilde{A}$ is a normal conditional distribution of land market price $P$, then there are:

$$
\tilde{A} \mid P \sim N\left(Z P, \sigma_{A}^{2}\right)
$$

Formula (9) indicates that the expected mortgage value of land will increase with the increase of land market price. According to the regulation of the banking supervision department, if the proportion of loan quota to the value of land mortgage is $k$, the bank executives will not be punished as $L / A \leq k$; as $L / A>k$, the bank executives will not be able to get private benefits and the bank will be fined by the banking supervision department. Based on the above assumptions, the conditional probability that bank executives successfully evade bank supervision and punishment by mastering land market price risk and seeking private interests is as follows:

$$
\gamma=P(L \leq k \tilde{A} \mid P)=P(\tilde{A} \geq L / k \mid P)
$$

By combining formulas (9) and (10), we can obtain:

$$
q=\mathrm{P}\left(\tilde{A} \geq \frac{L}{k} \mid P\right)=\int_{L / k}^{+\infty} \frac{1}{\sqrt{2 \pi} \sigma_{A}} \exp \left\{-\frac{(A-Z P)^{2}}{2 \sigma_{A}^{2}}\right\} d A
$$

Formula (11) calculates first-order and second-order partial derivatives of credit scale, respectively.

$$
\frac{\partial q}{\partial L}=-\frac{1}{\sqrt{2 \pi} k \sigma_{A}} \exp \left\{-\frac{(L / k-Z P)^{2}}{2 \sigma_{A}^{2}}\right\}<0
$$

Formula (11) derives the partial derivative of land price $P$ and finds that:

$$
\begin{aligned}
& \frac{\partial q}{\partial P}=\int_{L / k}^{+\infty} \frac{Z(A-Z P)}{\sqrt{2 \pi} \sigma_{A}^{3}} \exp \left\{-\frac{(A-Z P)^{2}}{2 \sigma_{A}^{2}}\right\} d A>0 \\
& \frac{\partial^{2} q}{\partial L^{2}}=\frac{(L / k-Z P)}{\sqrt{2 \pi} k^{2} \sigma_{A}^{3}} \exp \left\{-\frac{(L / k-Z P)^{2}}{2 \sigma_{A}^{2}}\right\}
\end{aligned}
$$

The partial derivative of formula (12) with respect to land price $P$ can be obtained by sorting out:

Based on the above, the following results can be obtained:

(1) $\partial q / \partial L<0, \partial q / \partial P>0$;

(2) $L<k Z P, \quad \partial^{2} q / \partial L \partial P>0, \partial^{2} q / \partial L^{2}<0$; $L>k Z P, \quad \partial^{2} q / \partial L \partial P<0, \partial^{2} q / \partial L^{2}>0$.

The above results show that the probability of not being prosecuted by bank supervisors tends to decrease when bank executives expand the scale of land lending; the probability of not being prosecuted by bank supervisors tends to increase when land market prices rise. 


\section{Bank credit demand for land hoarding of assembled buildings development by developers}

Assuming that the developer's bank credit demand mainly depends on the following variables, namely, the developer's willingness to pay the bank interest rate $\left(r_{L}\right)$ and the bank executive's willingness to pay the bank executive's private interest $(R)$ when the marginal land income at a certain price level is obtained, there are:

$$
\begin{cases}r_{L}=r_{L}(P) & r_{L}^{\prime}(P)>0 \\ R=R(P) & R^{\prime}(P)>0\end{cases}
$$

According to formulas (8) and (15), we can describe the unilateral equilibrium of credit market under the game of bank Executives' lending with the following models: $\max U_{B}=q R L+w\left[r_{L} L-r_{D} D-C(L, D)-(1-q) F\right]$

$$
\begin{aligned}
& \text { s.t. } \gamma=P(L \leq k \tilde{A} \mid P) \\
& r_{L}=r_{L}(P) \\
& R=R(P)
\end{aligned}
$$

Therefore, the first-order conditions for optimization are:

$$
\gamma R+R L \partial \gamma / \partial L+\theta\left(r_{L}-\partial C / \partial L+Q \partial \gamma / \partial L\right)=0
$$

The unilateral equilibrium of credit market is solved by (17) sorting it out as follows:

$$
r_{L}=\partial C / \partial L-Q \partial \gamma / \partial L-(\gamma R+R L \partial \gamma / \partial L) / \theta
$$

(1) When bank executives do not seek personal gain ( $R=0$ ), the equilibrium solution is as follows:

$$
r_{L}=\partial C / \partial L-Q \partial \gamma / \partial L
$$

Among them, $r_{L}$ represents the marginal return of bank loans, $\partial C / \partial L$ represents the marginal cost of bank loans, and $-Q \partial \gamma / \partial L$ represents the anticipated penalty imposed by the regulatory authorities for excessive lending by bank executives. In the case that bank executives do not seek self-interest, that is, $R=0$, $r_{L}=\partial C / \partial L,-Q \partial \gamma / \partial L=0$, assume that the balanced lending scale at this time is $L_{0}^{*}$.

(2) When the private interest of bank executives is positive $(R>0)$ and the marginal private interest is also positive (because $\gamma R L$ is the total private interest of bank executives, $\gamma R+R L \partial \gamma / \partial L$ is the marginal private interest of bank executives), then $\gamma R+R L \partial \gamma / \partial L>0$ is the marginal private interest of bank executives. If the scale $L=L_{0}^{*}$ of lending for personal gain is substituted in (12), $r_{L}=\partial C / \partial L>\partial C / \partial L-Q \partial \gamma / \partial L-(\gamma R+R L \partial \gamma / \partial L) / \theta$ . If $R>0$ and $\gamma R+R L \partial \gamma / \partial L>0$, the equilibrium lending scale is $L_{+}^{*}, \partial \gamma / \partial L<0$, then $L_{+}^{*}$ must satisfy $L_{+}^{*}>L_{0}^{*}$ and the marginal cost $\partial C / \partial L$ is larger. At this time, the equilibrium situation shows that bank executives will expand the scale of lending under the guidance of marginal self-interest to the scale of lending without seeking self-interest, and when $\theta$ is small, bank executives will be more inclined to adopt the strategy of credit scale expansion when salary incentives are seriously inadequate $^{[8]}$.

\section{Bilateral equilibrium model of credit- land market under the game of senior bankers' lending}

Consolidation (3) and (17) can obtain the bilateral equilibrium model of credit-land market under the loan game of bank executives:

$$
\left\{\begin{array}{l}
P=\frac{N\left(P^{*}+h\right) L}{2 Z h+N L} \\
\gamma R+R L \frac{\partial \gamma}{\partial L}+\theta\left(r_{L}-\frac{\partial C}{\partial L}+Q \frac{\partial \gamma}{\partial L}\right)=0
\end{array}\right.
$$

According to the above equilibrium model, it is impossible to find the specific equilibrium solutions of land price $P$ and credit scale $L$. However, if the exogenous variables are given, it can be proved that the model has a unique equilibrium solution $(L, P)$.

For the first derivative of land price $P$ on both sides of the second equation in the model, there are:

$\frac{d L}{d P}=\left(\theta \frac{\partial^{2} C}{\partial L^{2}}-R \frac{\partial \gamma}{\partial L}\right)^{-1}\left[\gamma \frac{d R}{d P}+R \frac{\partial \gamma}{\partial P}+L \frac{d R}{d P} \frac{\partial \gamma}{\partial L}+\theta \frac{d r_{L}}{d P}+(R L+\theta Q) \frac{\partial^{2} \gamma}{\partial L \partial P}\right]$

If bank executives do not seek self-interest $(R=0$ and $d R / d P=0$ ), then formula (21) can be changed to:

$$
\frac{d L}{d P}=\left(\frac{\partial^{2} C}{\partial L^{2}}\right)^{-1}\left(\frac{d r_{L}}{d P}+Q \frac{\partial^{2} \gamma}{\partial L \partial P}\right)
$$

According to $\partial^{2} C / \partial L^{2}>0$ and $L<k Z P$, then $\partial^{2} q / \partial L \partial P>0 . d L / d P>0, L>k Z P$, $d L / d P<0$. This shows that when the land price rises abnormally and the scale of lending is too inflated, both bank supervisors and bank executives will be aware of market changes. The probability of bank supervisors investigating commercial bank credit expansion will increase, and bank executives will take action to reduce the scale of lending. Comparing formula (21) and sum formula (22), we can get:

$$
B=\gamma \frac{d R}{d P}+R \frac{\partial \gamma}{\partial P}+L \frac{d R}{d P} \frac{\partial \gamma}{\partial L}+R L \frac{\partial^{2} \gamma}{\partial L \partial P}
$$

For the marginal private interest $(\gamma R+R L \partial \gamma / \partial L)$ of bank executives, the first derivative of land price $P$ is obtained. 


$$
\frac{\partial\left(\gamma R+R L \frac{\partial \gamma}{\partial L}\right)}{\partial P}=\gamma \frac{d R}{d P}+R \frac{\partial \gamma}{\partial P}+R L \frac{\partial^{2} \gamma}{\partial L \partial P}+R \frac{d L}{d P} \frac{\partial \gamma}{\partial L}+L \frac{d R}{d P} \frac{\partial \gamma}{\partial L}
$$

Formula (24) reflects the fluctuation of the marginal private interests of bank executives when land prices fluctuate in unit quantities. If $\partial^{2}(q R L) / \partial L \partial P>0$, that is, when land prices rise, the marginal private interests of bank executives will also increase, then $d L / d P>0$ and $B>\partial^{2}(q R L) / \partial L \partial P>0$.

\section{Conclusion}

Figure 1 is used to synthesize the above relationship. Among them, $L_{0}$ indicates the bank financial support curve of land market when bank executives do not seek private interests. $L_{+}$indicates that the marginal private interest of bank executives is positive, and the bank financial support curve of land market is positive.

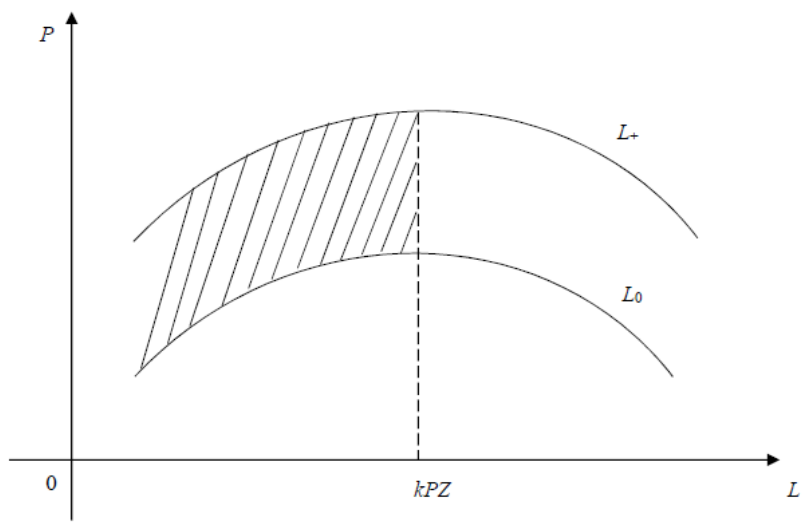

Figure 1. Relationship between land price, marginal private interest of bank executives' lending and bank financial support

As can be seen from Figure 1, when the marginal private interests of bank executives do not seek private interests or seek private interests increase with the increase of land prices, as long as the scale of financial support is smaller than the maximum loan size ( $L<k P Z$ ) stipulated by the banking regulatory authorities, with the rise of land prices, the optimistic expectations of bank executives on the value of land will continue to improve ( $k$ increases) or produce stronger marginal private interests ${ }^{[9]}$. In pursuit, bank executives will expand the scale of lending. With the strong support of bank finance, developers "seize cities and grab land", constantly pushing up land prices, which in turn prompts banks to increase financial support ( $L$ increases), and further increase land prices ${ }^{[10]}$. After joining the government factors, the interest induction of "making money from the land" will further aggravate the rise of land prices. Therefore, the relationship between land price, marginal private interest of bank Executives' lending and bank financial support can be roughly described as a vicious circular transmission mechanism that "developers (government) push up land price $\rightarrow$ expansion of land credit scale $\rightarrow$ higher land price level $\rightarrow$ stronger financial support".

\section{Acknowledgments}

This research project was supported by the Science and Technology Tackling Project of Zhanjiang, Innovation and Strong School Project funding of Guangdong institute of Arts and Sciences and the Special Funds for Education Development at Guangdong Provincial Level in 2019 (Development Direction of Private Education). Financial support was gratefully acknowledged. All errors were the sole responsibility of the authors. The authors wished to thank Chuansheng Luo, Xianying Hu, Anxing Wang, Changli Li for their helpful comments and suggestions. The authors also wished to acknowledge assistance and encouragement from colleagues of the department of civil and construction engineering.

\section{References}

1. White, P. (1986) Land availability, land banking and the price of land for housing: a review of recent debates. Joumal of Property Research. Commun., 3: 101-111.

2. Tse, R.Y.C. (1998) Housing price, land supply and revenue from land sales. Urban Studies. Commun., 35: $1377-1392$.

3. Gillen M., Fisher, P. (2002) Residential developer behavior in land price determination. Joumal of Property Research. Commun., 19: 39-45.

4. Barlow, J. (1993) Controlling the housing land market: some examples from Europe. Urhan Studies. Commun., 30: 1129-1149.

5. Ball, M., Lizieri C., MacGregor B. (1998) The economics of cammercial property markets. Roudedge, London.

6. Titman, S. (1985) Urban land prices under uncertainty. American Economic Review. Commun., 75: 505-514.

7. Gao, B., Hong, T. (2008) Herding behavior in China's housing market: empirical analysis based on dynamic panel model 1995-2005. Managment World. Commun., 3: 52-59.

8. Lv, J.L. (2014) China's urban housing market bubble. Economic Research. Commun., 6: 55-58.

9. Abraham, J.M., Hendershott, P.H. (1996) Bubbles in metropolitan housing markets. Journal of Housing Research. Commun., 7: 191-207.

10. Liu, H.Y., Ren R.R. (2008) Analysis of land reserve and bidding behavior of developers. China Land Science. Commun., 12: 12-16. 